Virginia Commonwealth University vCU Scholars Compass

1998

\title{
Quality of Life and Clinical Outcomes in Elderly Patients Treated with Ventricular Pacing as Compared with Dual-Chamber Pacing
}

Gervasio A. Lamas , M.D.

University of Miami

E. John Orav, Ph.D.

Brigham and Women's Hospital and Harvard Medical School

Bruce S. Stambler, M.D.

McGuire Veterans Affairs Medical Center

See next page for additional authors

Follow this and additional works at: http://scholarscompass.vcu.edu/intmed_pubs

Part of the Medicine and Health Sciences Commons

From The New England Journal of Medicine, Lamas, G.A., Orav, E.J., Stambler, B.S., et al., Quality of Life and Clinical Outcomes in Elderly Patients Treated with Ventricular Pacing as Compared with Dual-Chamber Pacing, Vol. 338, Page 1097, Copyright ( 1998 Massachusetts Medical Society. Reprinted with permission.

\section{Downloaded from}

http://scholarscompass.vcu.edu/intmed_pubs/57

This Article is brought to you for free and open access by the Dept. of Internal Medicine at VCU Scholars Compass. It has been accepted for inclusion in Internal Medicine Publications by an authorized administrator of VCU Scholars Compass. For more information, please contact libcompass@vcu.edu. 


\section{Authors}

Gervasio A. Lamas , M.D.; E. John Orav , Ph.D.; Bruce S. Stambler , M.D.; Kenneth A. Ellenbogen , M.D.; Elena B. Sgarbossa , M.D.; Shoei K. Stephen Huang, M.D.; Roger A. Marinchak , M.D.; N.A. Mark Estes , M.D.; Gary F. Mitchell , M.D.; Eric H. Lieberman , M.D.; Carol M. Mangione , M.D.; Lee Goldman , M.D.; John J. Griffin; James D. Maloney; Carlos Rizo-Patrón; Ferdinand J. Venditti; and Bruce L. Wilkoff 


\title{
QUALITY OF LIFE AND CLINICAL OUTCOMES IN ELDERLY PATIENTS TREATED WITH VENTRICULAR PACING AS COMPARED WITH DUAL-CHAMBER PACING
}

\author{
Gervasio A. Lamas, M.D., E. John Orav, Ph.D., Bruce S. Stambler, M.D., Kenneth A. Ellenbogen, M.D., \\ Elena B. Sgarbossa, M.D., Shoei K. Stephen Huang, M.D., Roger A. Marinchak, M.D., N.A. Mark Estes III, M.D., \\ Gary F. Mitchell, M.D., Eric H. Lieberman, M.D., Carol M. Mangione, M.D., \\ and Lee Goldman, M.D., for the Pacemaker Selection in the Elderly Investigators*
}

\begin{abstract}
Background Standard clinical practice permits the use of either single-chamber ventricular pacemakers or dual-chamber pacemakers for most patients who require cardiac pacing. Ventricular pacemakers are less expensive, but dual-chamber pacemakers are believed to be more physiologic. However, it is not known whether either type of pacemaker results in superior clinical outcomes.

Methods The Pacemaker Selection in the Elderly study was a 30-month, single-blind, randomized, controlled comparison of ventricular pacing and dualchamber pacing in 407 patients 65 years of age or older in 29 centers. Patients received a dual-chamber pacemaker that had been randomly programmed to either ventricular pacing or dual-chamber pacing. The primary end point was health-related quality of life as measured by the 36-item Medical Outcomes Study Short-Form General Health Survey.

Results The average age of the patients was 76 years (range, 65 to 96 ), and 60 percent were men. Quality of life improved significantly after pacemaker implantation $(P<0.001)$, but there were no differences between the two pacing modes in either the quality of life or prespecified clinical outcomes (including cardiovascular events or death). However, 53 patients assigned to ventricular pacing (26 percent) were crossed over to dual-chamber pacing because of symptoms related to the pacemaker syndrome. Patients with sinus-node dysfunction, but not those with atrioventricular block, had moderately better quality of life and cardiovascular functional status with dual-chamber pacing than with ventricular pacing. Trends of borderline statistical significance in clinical end points favoring dual-chamber pacing were observed in patients with sinus-node dysfunction, but not in those with atrioventricular block.

Conclusions The implantation of a permanent pacemaker improves health-related quality of life. The quality-of-life benefits associated with dualchamber pacing as compared with ventricular pacing are observed principally in the subgroup of patients with sinus-node dysfunction. (N Engl J Med 1998;338:1097-104.)

(C1998, Massachusetts Medical Society.
\end{abstract}

$\mathrm{P}$ ACEMAKER technology and clinical practice in the United States permit the use of either single-chamber ventricular pacemakers or dual-chamber pacemakers for patients who require cardiac pacing. To date, the choice of cardiac pacemaker has not been based on the results of clinical trials. Ventricular pacemakers are less expensive, are simpler to implant and monitor, and have a longer service life than dual-chamber pacemakers. However, dual-chamber systems preserve atrioventricular synchrony and may be more physiologic. ${ }^{1}$ Some studies have suggested that as compared with patients with ventricular pacemakers, those with dual-chamber pacemakers have a better healthrelated quality of life. ${ }^{2,3}$ However, those small, crossover studies have had inconsistent blinding, have occasionally used nonstandard means to measure quality of life, and have been unable to assess whether improvements in the quality of life are maintained during long-term follow-up. The purpose of the Pacemaker Selection in the Elderly trial was to assess the effect of the pacing mode on the long-term health-related quality of life of elderly patients with pacemakers.

\section{METHODS}

The study was a single-blind, randomized, controlled comparison of ventricular pacing and dual-chamber pacing involving 29 centers. On the basis of statistical-power calculations, $400 \mathrm{pa}-$ tients were required in order to have a power of more than 80 percent to detect a clinically meaningful difference in the quality

From the Division of Cardiology, Mount Sinai Medical Center, and the University of Miami School of Medicine, Miami Beach, Fla. (G.A.L., E.H.L.); the Section of Clinical Epidemiology (E.J.O.) and the Cardiovascular Division (G.F.M.), Brigham and Women's Hospital and Harvard Medical School, Boston; the McGuire Veterans Affairs Medical Center (B.S.S.) and the Medical College of Virginia Hospital (K.A.E.), Richmond; the Cleveland Clinic Foundation, Cleveland (E.B.S.); National Taiwan University College of Medicine, Taipei, Taiwan (S.K.S.H.); Lankenau Hospital, Wynnewood, Pa. (R.A.M.); Tufts-New England Medical Center, Boston (N.A.M.E.); the University of California, Los Angeles, Los Angeles (C.M.M.); and the University of California, San Francisco, San Francisco (L.G.). Address reprint requests to Dr. Lamas at the Division of Cardiology, Mount Sinai Medical Center, 4300 Alton Rd., Miami Beach, FL 33140 .

Other authors were John J. Griffin, M.D. (Virginia Beach General Hospital, Virginia Beach, Va.), James D. Maloney, M.D., and Carlos RizoPatrón, M.D. (Baylor Medical Center, Dallas), Ferdinand J. Venditti, M.D. (Lahey Clinic Foundation, Burlington, Mass.), and Bruce L. Wilkoff, M.D. (Cleveland Clinic Foundation, Cleveland).

*The other principal investigators of the Pacemaker Selection in the Elderly trial are listed in the Appendix. 
of life between treatment groups. Blocked randomization lists were produced centrally for each site. Patient recruitment began February 26, 1993, and ended September 30, 1994, when 407 patients had been enrolled. The patients were followed and clinical end points were assessed until the initiation of the close-out procedure, which began June 1, 1995, and ended August 31, 1995. After the close-out procedure was completed, the patients' quality of life was assessed by telephone interviews through June 30,1996 . The average follow-up for clinical end points was 550 days (range, 216 to 996 ).

All patients were 65 years of age or older, were in sinus rhythm, required a permanent pacemaker for the prevention or treatment of bradycardia, ${ }^{4}$ and gave written informed consent for research participation. Intermedics dual-chamber rate-adaptive pacemakers (models 294-03, 293-03, 294-03R, and 294-05) were implanted. Patients were excluded from the study if they could not participate in the quality-of-life assessments, had clinically overt congestive heart failure at the time of implantation, had had atrial fibrillation without any documented sinus mechanism for more than six months, had serious noncardiac illness, or had inadequate atrial-capture or sensing thresholds.

\section{Implantation and Programming}

Once both atrial and ventricular leads had been positioned, a randomization envelope was opened. The pacemaker was programmed to ventricular or dual-chamber pacing before implantation. Randomization was stratified according to clinical site. Initial programming in both groups required the use of rate adaptation, which allows a sensor-based increase in the heart rate proportional to a patient's activity. Therefore, the formal mode designations for the study were DDDR (atrial and ventricular pacing, atrial and ventricular sensing, dual response, rate-adaptive) for dual-chamber pacemakers and VVIR (ventricular pacing, ventricular sensing, inhibition response, rate-adaptive) for ventricular pacemakers. ${ }^{5}$ For both groups, a lower rate limit of at least 50 beats per minute was required, and an upper limit of less than 130 beats per minute was suggested. Programming of all other features was left to the discretion of the investigators.

\section{Patient Monitoring}

Follow-up visits and health-status assessments took place 3, 9, and 18 months after enrollment and at the end of the study. The assessment of health status before randomization was performed at the local clinical site, before the pacemaker mode was assigned. Subsequent assessments were made by telephone from the coordinating center by two experienced telephone interviewers who were unaware of the patients' mode assignments. The first interviewer conducted 98 percent of the 3 -month interviews, whereas the second interviewer conducted 98 percent of the 9 -month interviews and 99 percent of the 18-month interviews.

Multidimensional health-related quality of life was assessed with the 36-item Medical Outcomes Study Short-Form General Health Survey (SF-36) ${ }^{6}$ which includes one multi-item scale measuring eight health-related aspects: physical function, social function, physical role, emotional role, mental health, energy, pain, and general health perceptions. The score on each of the eight health concepts ranges from 0 (worst) to 100 (best). For example, the average physical-function score for a healthy 70 -year-old person is 69 , whereas the average score for a patient of similar age but with congestive heart failure is $48 .^{7}$ Disease-specific cardiovascular functional status was measured with the Specific Activity Scale. ${ }^{8}$ The score on this four-point scale ranges from 1 (best) to 4 (worst). We validated the SF-36 by comparing subgroups of study patients with diagnoses known to affect quality of life, such as heart failure or angina, and those without such diagnoses.

\section{End Points}

The primary end point was health-related quality of life as measured by the SF-36. In addition, we compared the following prespecified secondary clinical end points between groups: death from all causes; first nonfatal stroke or death; first hospitalization for heart failure, first nonfatal stroke, or death; development of atrial fibrillation; and development of the pacemaker syndrome. All the components of the composite end points were chosen on the basis of data in the pacing literature suggesting the potential for improvement with atrial-based pacing. ${ }^{9}$ The pacemaker syndrome (which is related to a sustained loss of synchronous atrioventricular contraction) was defined as the presence of left-sided or right-sided heart failure in association with ventricular pacing or of symptomatic hypotension with a drop in blood pressure of $20 \mathrm{~mm} \mathrm{Hg}$ or more during ventricular pacing. We also analyzed prespecified subgroups of patients with a diagnosis at implantation of sinus-node dysfunction or atrioventricular block.

\section{Statistical Analysis}

Base-line characteristics were compared between treatment groups with use of Wilcoxon's rank-sum test for continuous measures and Fisher's exact test for categorical variables. We used Wilcoxon's signed-rank tests for paired data to assess changes that occurred after randomization in all patients and changes that occurred after crossover to dual-chamber pacing in patients with ventricular pacing. All analyses were based on the intention to treat. Scores for the SF-36 subscales were compared between modes at each period with a multiple linear regression analysis, with adjustment for sex, quartile of age, and the base-line score for the specific subscale. Scores for the Specific Activity Scale were compared between treatment groups with an ordinal logistic regression adjusted for sex, quartile of age, and base-line score for the specific patient. In addition, longitudinal mode-related differences were analyzed with generalized estimating equations. ${ }^{10}$ For scores for the SF-36 subscales, a repeated-measures linear regression was used. For the scores for the Specific Activity Scale, the general-estimating-equation analogue of a binomial model was used. The design of the study necessarily permitted reprogramming from ventricular to dual-chamber pacing if severe pacemaker syndrome developed in patients assigned to ventricular pacing. In each such patient, scores for the SF-36 and Specific Activity Scale were assessed before crossover, and these scores were carried forward for subsequent statistical analyses of quality of life. The length of time to the occurrence of the clinical end points in each group was compared visually with use of Kaplan-Meier curves ${ }^{11}$ and inferentially with use of the Cox proportional-hazards method $^{12}$ adjusted for sex and quartile of age. For all analyses, the $P$ values were two-tailed, and a $P$ value of less than 0.05 was considered to indicate statistical significance.

\section{RESULTS}

\section{Base-Line Characteristics}

The average age of the patients was 76 (range, 65 to 96 ), and 60 percent were men. Over 70 percent of the overall population was in New York Heart Association class I or II. Twenty-nine percent of the patients had a history of supraventricular tachycardia, including atrial fibrillation, and 27 percent had a history of heart failure. Cerebrovascular disease was present at base line in 13 percent. The ejection fraction was known in the case of 254 patients (62 percent) and was normal in 56 percent of these. Antiarrhythmic therapy was in use in 17 percent of patients. There were no significant differences in any of the base-line characteristics between groups (Table 1).

\section{Indications for and Characteristics of the Pacemakers}

The indications for the implantation of a permanent pacemaker included atrioventricular block in 
Table 1. Base-Line Characteristics of the Patients.*

\begin{tabular}{|c|c|c|}
\hline Characteristic & $\begin{array}{l}\text { Single-ChAmber } \\
\text { Ventricular PACING } \\
(\mathbf{N}=\mathbf{2 0 4})\end{array}$ & $\begin{array}{c}\text { Dual-CHAMBer } \\
\text { Pacing } \\
(\mathbf{N}=\mathbf{2 0 3})\end{array}$ \\
\hline Age $(y r)$ & $76 \pm 6$ & $76 \pm 7$ \\
\hline Male sex (\%) & 62 & 57 \\
\hline Nonwhite race (\%) & 14 & 12 \\
\hline NYHA class I or II (\%) & 73 & 70 \\
\hline \multicolumn{3}{|l|}{ History (\%) } \\
\hline Diabetes & 25 & 29 \\
\hline Hypertension & 51 & 52 \\
\hline Myocardial infarction & 33 & 33 \\
\hline Heart failure & 28 & 26 \\
\hline Depressed ejection fraction & 25 & 27 \\
\hline Supraventricular tachycardia & 30 & 27 \\
\hline Cerebrovascular disease & 14 & 12 \\
\hline Chronic lung disease & 13 & 14 \\
\hline Any tumor & 8 & 10 \\
\hline \multicolumn{3}{|l|}{ Prior procedures or operations (\%) } \\
\hline Coronary bypass surgery & 22 & 23 \\
\hline Mitral-valve surgery & 3 & 3 \\
\hline Aortic-valve surgery & 4 & 4 \\
\hline Coronary angioplasty & 7 & 10 \\
\hline Implantation of defibrillator & 1 & 1 \\
\hline Radiofrequency ablation & 1 & 1 \\
\hline \multicolumn{3}{|l|}{ Concomitant medications (\%) } \\
\hline $\begin{array}{l}\text { Angiotensin-converting- } \\
\text { enzyme inhibitors }\end{array}$ & 27 & 31 \\
\hline Amiodarone & 5 & 4 \\
\hline Aspirin & 37 & 41 \\
\hline$\beta$-Adrenergic blockers & 16 & 9 \\
\hline Calcium antagonists & 24 & 26 \\
\hline Warfarin & 4 & 6 \\
\hline Digitalis & 23 & 17 \\
\hline Diuretics & 36 & 34 \\
\hline Flecainide & 2 & 2 \\
\hline Procainamide & 5 & 7 \\
\hline Quinidine & 1 & 2 \\
\hline Sotalol & 3 & 4 \\
\hline
\end{tabular}

*Plus-minus values are means \pm SD. NYHA denotes New York Heart Association. There were no significant differences between groups.

201 patients (49 percent, of whom 119 patients, or 59 percent, had third-degree block), sinus-node dysfunction in 175 patients (43 percent), and other diagnoses in 31 ( 8 percent). Ventriculoatrial (retrograde) conduction at the time of implantation was present in 29 percent. There were no important differences in capture and sensing thresholds between groups at the time of implantation (Table 2).

\section{Pacemaker Syndrome}

During the course of the trial, pacemaker syndrome severe enough to warrant reprogramming from ventricular to dual-chamber pacing was diagnosed in 53 patients assigned to ventricular pacing (26 percent), in 45 percent of whom sinus-node dysfunction was the reason for implantation. Crossover from ventricular to dual-chamber pacing occurred early: 44 percent of the 53 crossovers occurred within one month after implantation, and 77
Table 2. Characteristics of the Pacemakers.*

\begin{tabular}{|c|c|c|c|}
\hline ChaRACtERISTIC & $\begin{array}{l}\text { Ventricular } \\
\text { Pacing } \\
\text { (N=204) }\end{array}$ & $\begin{array}{c}\text { DuAl-Chamber } \\
\text { PACING } \\
(\mathbf{N}=\mathbf{2 0 3})\end{array}$ & P Value \\
\hline P-wave amplitude (mV) & $3.2 \pm 1.5$ & $3.0 \pm 1.3$ & 0.29 \\
\hline Atrial-capture threshold $(\mathrm{V}) \dagger$ & $1.0 \pm 0.4$ & $1.0 \pm 0.4$ & 0.33 \\
\hline R-wave amplitude (mV) & $12.8 \pm 5.3$ & $12.0 \pm 5.2$ & 0.16 \\
\hline $\begin{array}{l}\text { Ventricular-capture } \\
\text { threshold }(\mathrm{V}) \dagger\end{array}$ & $0.5 \pm 0.2$ & $0.6 \pm 0.3$ & 0.02 \\
\hline $\begin{array}{l}\text { Ventriculoatrial conduc- } \\
\text { tion at implantation } \\
\text { (\% of patients) } \ddagger\end{array}$ & 29 & 29 & 1.00 \\
\hline
\end{tabular}

*Plus-minus values are means \pm SD.

†Capture threshold was measured at a pulse width of $0.5 \mathrm{msec}$.

‡Ventriculoatrial conduction was assessed by ventricular pacing at 70 and 100 beats per minute.

percent within six months (Fig. 1). Although multiple symptoms were recorded in each patient, the clinical manifestations were fatigue in all patients, dyspnea or effort intolerance in 67 percent, orthopnea or paroxysmal nocturnal dyspnea in 24 percent, presyncope in 33 percent, and a feeling of fullness in the neck in 20 percent. After crossover, the patients had improvement in SF-36 scores, including scores for physical function $(+22, \mathrm{P}=0.03)$ and emotional role $(+27, \mathrm{P}=0.01)$.

\section{Other Changes in Assigned Mode}

Four patients ( 2 percent) who were initially assigned to dual-chamber pacing had their pacemakers reprogrammed to single-chamber ventricular pacing during the course of the study because chronic atrial fibrillation or supraventricular tachycardia developed $(\mathrm{P}<0.001$ for the comparison with the crossover rate in the ventricular-pacing group).

\section{Validation of SF-36}

Patients with a history of heart failure at base line were compared with those without such a history. There was a 13-point difference in scores for the physical-function subscale of SF-36 (44 vs. $57, \mathrm{P}<0.001$ ) and a 13-point difference in scores for the physicalrole subscale ( 25 vs. $38, \mathrm{P}=0.004)$. Patients with a base-line history of angina were compared with those without angina. There was a 10 -point difference in scores for the physical-function subscale ( 47 vs. 57 , $\mathrm{P}=0.001)$ and a 14-point difference in scores for the physical-role subscale ( 25 vs. $39, \mathrm{P}=0.002$ ).

\section{Quality of Life}

In the overall group, there was significant improvement in health-related quality of life between base line (before implantation) and three months after implantation, as measured by several SF-36 subscales (social function, $\mathrm{P}<0.001$; physical role, 


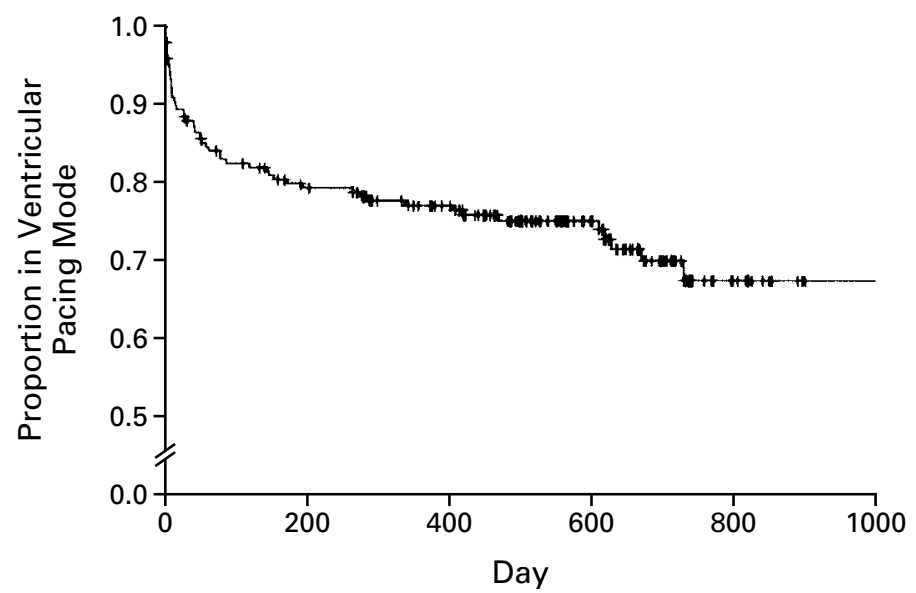

Figure 1. Kaplan-Meier Curve of the Proportion of Patients Assigned to Ventricular Pacing Who Did Not Cross Over to Dual-Chamber Pacing.

The tick marks represent the time to crossover or the end of follow-up.

$\mathrm{P}<0.001$; emotional role, $\mathrm{P}<0.001$; mental health, $\mathrm{P}<0.001$; energy, $\mathrm{P}<0.001)$. In contrast, there were no significant differences in scores between the ventricular-pacing group and the dual-chamber-pacing group in any of the SF-36 subscales at 3 months or 18 months. After nine months of follow-up, there was a significant difference favoring dual-chamber pacing only in scores for the mental health subscale $(\mathrm{P}=0.03)$ (Table 3$)$. Longitudinal analyses, however, detected a borderline improvement in scores on the emotional-role subscale in patients assigned to dual-chamber pacing $(\mathrm{P}=0.04)$. There were no significant differences in cardiovascular functional status between groups, as assessed by the Specific Activity Scale, at either the three-month or the ninemonth assessment. However, there was a significant difference favoring dual-chamber pacing at the 18 month visit (Table 4), and longitudinal analysis demonstrated a significant difference favoring dual-chamber pacing $(\mathrm{P}=0.045)$.

\section{Clinical Events}

There were no significant differences between the ventricular-pacing group and the dual-chamberpacing group in the rates of death from all causes, stroke or death, stroke or death or hospitalization for heart failure, and the development of atrial fibrillation (Table 5).

\section{Analysis of Prespecified Subgroups}

\section{Sinus-Node Dysfunction}

Among the patients who received pacemakers because of sinus-node dysfunction, there were significant differences favoring dual-chamber pacing at three months in scores on the physical-role subscale
$(\mathrm{P}=0.02)$, social-function subscale $(\mathrm{P}=0.03)$, and emotional-role subscale $(\mathrm{P}=0.002)$ of $\mathrm{SF}-36$. Although in the later assessments there were no significant differences between treatment groups at each time point, longitudinal analyses demonstrated better scores on the emotional-role subscale $(\mathrm{P}=0.001)$ and social-function subscale $(\mathrm{P}=0.02)$ in the patients assigned to dual-chamber pacing. Longitudinal analysis of scores on the Specific Activity Scale demonstrated a significant difference favoring dualchamber pacing $(\mathrm{P}=0.02)$. Furthermore, there were trends of borderline significance in clinical end points favoring dual-chamber pacing (Table 5).

\section{Atrioventricular Block}

Among the patients with atrioventricular block at implantation, there were no significant differences between groups in any of the SF-36 subscales, in longitudinal analyses of the Specific Activity Scale, or in any of the prespecified clinical end points (Table 5).

\section{DISCUSSION}

Industry sources estimate that nearly 190,000 pacemakers will be implanted in patients in the United States in 1998, a substantial increase since 1989, when 110,500 devices were implanted. ${ }^{13} \mathrm{Al}$ though dual-chamber pacemakers have been in common use for nearly two decades, the effect of the type of pacemaker on the long-term healthrelated quality of life of elderly pacemaker recipients has not been adequately studied.

Over 70 percent of pacemaker recipients are at least 70 years old, ${ }^{14}$ and there are sound physiologic reasons to expect that maintenance of atrioventricular synchrony with a dual-chamber pacemaker might 
Table 3. Quality of Life before and after Pacemaker Implantation, According to the Scores on the SF-36.*

\begin{tabular}{|c|c|c|c|c|c|c|c|c|c|c|c|c|}
\hline \multirow[t]{2}{*}{ VARIABLE } & \multicolumn{3}{|c|}{ BASE LINE } & \multicolumn{3}{|c|}{3 Months } & \multicolumn{3}{|c|}{9 Months } & \multicolumn{3}{|c|}{18 Months } \\
\hline & $\begin{array}{c}\text { VVIR } \\
(\mathrm{N}=204)\end{array}$ & $\begin{array}{c}\text { DDDR } \\
(\mathrm{N}=203)\end{array}$ & $\begin{array}{c}P \\
\text { VALUE }\end{array}$ & $\begin{array}{c}\text { VVIR } \\
(\mathrm{N}=167)\end{array}$ & $\begin{array}{c}\text { DDDR } \\
(\mathrm{N}=160)\end{array}$ & $\begin{array}{c}P \\
\text { VALUE }\end{array}$ & $\begin{array}{c}\text { VVIR } \\
(\mathrm{N}=165)\end{array}$ & $\begin{array}{c}\text { DDDR } \\
(\mathrm{N}=163)\end{array}$ & $\begin{array}{c}P \\
\text { VALUE }\end{array}$ & $\begin{array}{c}\text { VVIR } \\
(\mathrm{N}=150)\end{array}$ & $\begin{array}{c}\text { DDDR } \\
(\mathrm{N}=138)\end{array}$ & $\begin{array}{c}P \\
\text { VALUE }\end{array}$ \\
\hline \multirow{2}{*}{$\begin{array}{l}\text { Percentage of eligible } \\
\text { patients evaluated }\end{array}$} & 100 & 100 & & 85 & 81 & & 88 & 87 & & 92 & 88 & \\
\hline & \multicolumn{2}{|c|}{ score } & & \multicolumn{2}{|c|}{ score } & & \multicolumn{2}{|c|}{ score } & & \multicolumn{2}{|c|}{ score } & \\
\hline \multicolumn{13}{|l|}{ Subscale } \\
\hline Physical function & 52.9 & 54.4 & 0.55 & 53.9 & 56.9 & 0.23 & 54.0 & 57.5 & 0.22 & 58.4 & 58.4 & 0.99 \\
\hline Social function & 61.3 & 63.4 & 0.45 & 73.0 & 75.3 & 0.37 & 67.3 & 69.2 & 0.54 & 68.0 & 69.9 & 0.54 \\
\hline Physical role & 33.4 & 35.9 & 0.54 & 53.6 & 62.8 & 0.051 & 49.0 & 53.2 & 0.36 & 53.7 & 55.1 & 0.78 \\
\hline Emotional role & 70.6 & 67.2 & 0.41 & 83.8 & 90.6 & 0.052 & 76.5 & 81.1 & 0.27 & 76.1 & 80.6 & 0.31 \\
\hline Mental health & 73.0 & 71.9 & 0.59 & 77.0 & 77.6 & 0.73 & 75.2 & 79.0 & 0.03 & 73.0 & 76.5 & 0.09 \\
\hline Energy & 43.9 & 42.3 & 0.52 & 53.0 & 55.0 & 0.35 & 50.3 & 50.5 & 0.92 & 50.1 & 50.1 & 0.99 \\
\hline Pain & 67.3 & 66.1 & 0.67 & 69.7 & 69.4 & 0.91 & 72.1 & 70.9 & 0.64 & 68.2 & 70.6 & 0.42 \\
\hline Health perception & 60.3 & 60.3 & 0.97 & 62.3 & 62.2 & 0.99 & 58.4 & 58.3 & 0.95 & 58.3 & 56.2 & 0.33 \\
\hline
\end{tabular}

${ }^{*}$ The numbers of patients are the numbers eligible for evaluation. VVIR denotes rate-adaptive single-chamber ventricular pacing, and DDDR rate-adaptive dual-chamber pacing. Means and $\mathrm{P}$ values were adjusted by multiple regression for sex and quartile of age and, at follow-up, for base-line functional status. Patients who died were excluded from the analysis, and patients who enrolled too late for the 18 -month interview were not included in the analysis at 18 months.

\begin{tabular}{|c|c|c|c|c|c|c|c|c|}
\hline \multirow[t]{2}{*}{ VARIABLE } & \multicolumn{2}{|c|}{ BASE LINE } & \multicolumn{2}{|c|}{3 MONTHS } & \multicolumn{2}{|c|}{9 MONTHS } & \multicolumn{2}{|c|}{18 Months } \\
\hline & $\begin{array}{c}\text { VVIR } \\
(\mathrm{N}=204)\end{array}$ & $\begin{array}{c}\text { DDDR } \\
(\mathrm{N}=203)\end{array}$ & $\begin{array}{c}\text { VVIR } \\
(\mathrm{N}=159)\end{array}$ & $\begin{array}{c}\mathrm{DDDR} \\
(\mathrm{N}=158)\end{array}$ & $\begin{array}{l}\text { VVIR } \\
(\mathrm{N}=155)\end{array}$ & $\begin{array}{c}\text { DDDR } \\
(\mathrm{N}=161)\end{array}$ & $\begin{array}{l}\text { VVIR } \\
(\mathrm{N}=141)\end{array}$ & $\begin{array}{c}\text { DDDR } \\
(\mathrm{N}=136)\end{array}$ \\
\hline \multirow{2}{*}{$\begin{array}{l}\text { Percentage of } \\
\text { eligible patients } \\
\text { evaluated }\end{array}$} & 100 & 100 & 81 & 80 & 83 & 86 & 87 & 87 \\
\hline & \multicolumn{8}{|c|}{ percentage of patients } \\
\hline \multicolumn{9}{|l|}{$\begin{array}{l}\text { Score on Specific } \\
\text { Activity Scale }\end{array}$} \\
\hline 1 (best) & 37 & 39 & 41 & 44 & 47 & 55 & 46 & 60 \\
\hline 2 & 25 & 20 & 22 & 27 & 25 & 22 & 23 & 15 \\
\hline 3 & 37 & 38 & 34 & 27 & 26 & 23 & 26 & 24 \\
\hline 4 (worst) & 1 & 2 & 3 & 3 & 3 & 1 & 6 & 1 \\
\hline$P$ value & \multicolumn{2}{|c|}{0.71} & \multicolumn{2}{|c|}{0.22} & \multicolumn{2}{|c|}{0.23} & \multicolumn{2}{|c|}{0.02} \\
\hline
\end{tabular}

*The numbers of patients are the numbers eligible for evaluation. VVIR denotes rate-adaptive single-chamber ventricular pacing, and DDDR rate-adaptive dual-chamber pacing. Patients who died were excluded from the analysis, and patients enrolled too late for the 18 -month interview were not included in the analysis at 18 months. P values and proportions shown are from an unadjusted chi-square test for trend.

be desirable in elderly patients. ${ }^{15,16}$ However, dualchamber pacemakers are more expensive and more difficult to implant and monitor than single-chamber ventricular pacemakers, and dual-chamber pacemakers carry a risk of complications in two leads, not just one. ${ }^{17}$ In the present cohort, pacemaker placement led to dramatic improvements in healthrelated quality of life. This uncontrolled observation is consistent with the reported low rate of recurrence of symptoms after pacemaker implantation. ${ }^{18} \mathrm{How}^{-}$ ever, when patients with ventricular pacing were compared with patients with dual-chamber pacing, there were no convincing differences in general health-related quality of life. Analysis of two prespecified subgroups - patients with sinus-node dysfunction and those with atrioventricular block at implantation - did reveal a favorable response to dual-chamber pacing in patients with sinus-node dysfunction. Nonetheless, these differences are considerably smaller than were previously thought. In contrast to the pattern observed with respect to general quality of life in the overall group, the Specific Activity Scale, an instrument that specifically measures the physical limitations associated with cardio- 
Table 5. Analysis of the End Points in the Group as a Whole and among Patients with Sinus-Node Dysfunction or Atrioventricular Block at Implantation.*

\begin{tabular}{|c|c|c|c|c|c|c|c|c|c|}
\hline \multirow[t]{2}{*}{ Prespecified End Point } & \multicolumn{3}{|c|}{ Overall Population } & \multicolumn{3}{|c|}{ Sinus-Node Dysfunction } & \multicolumn{3}{|c|}{ Atrioventricular Block } \\
\hline & $\begin{array}{c}\text { VVIR } \\
(\mathrm{N}=204)\end{array}$ & $\begin{array}{c}\text { DDDR } \\
(\mathrm{N}=203)\end{array}$ & P VAlue & $\begin{array}{c}\text { VVIR } \\
(\mathrm{N}=85)\end{array}$ & $\begin{array}{c}\text { DDDR } \\
(\mathrm{N}=90)\end{array}$ & P VAlue & $\begin{array}{c}\text { VVIR } \\
(\mathrm{N}=102)\end{array}$ & $\begin{array}{l}\text { DDDR } \\
(\mathrm{N}=99)\end{array}$ & P value \\
\hline & \multicolumn{2}{|c|}{ no. (\%) } & & \multicolumn{2}{|c|}{ no. $(\%)$} & & \multicolumn{2}{|c|}{ no. $(\%)$} & \\
\hline Death from all causes & $34(17)$ & $32(16)$ & 0.95 & $17(20)$ & $11(12)$ & 0.09 & $15(15)$ & $17(17)$ & 0.41 \\
\hline Stroke or death from any cause & $39(19)$ & $35(17)$ & 0.75 & $19(22)$ & $12(13)$ & 0.11 & $18(18)$ & $18(18)$ & 0.68 \\
\hline $\begin{array}{l}\text { Stroke or hospitalization for heart failure } \\
\text { or death from any cause }\end{array}$ & $56(27)$ & $44(22)$ & 0.18 & $26(31)$ & $18(20)$ & 0.07 & $27(26)$ & $21(21)$ & 0.49 \\
\hline Atrial fibrillation & $38(19)$ & $35(17)$ & 0.80 & $24(28)$ & $17(19)$ & 0.06 & $11(11)$ & $16(16)$ & 0.26 \\
\hline
\end{tabular}

*VVIR denotes rate-adaptive single-chamber ventricular pacing, and DDDR rate-adaptive dual-chamber pacing.

vascular disease, detected differences favoring dualchamber pacing that increased over time and were significant in longitudinal analyses.

Prior studies have suggested a measurably superior quality of life in patients with dual-chamber pacing, and on the basis of these studies we expected dual-chamber pacing to have a greater benefit than we actually found. There are important methodologic differences that may account for our divergent results. Some studies have used a short-term crossover design ${ }^{19}$ or measured quality of life with nonstandard instruments that have not been validated. ${ }^{2}$ We measured quality of life with a standard instrument and validated it against known disease states within the study population. Follow-up in crossover studies is short, and the long-term effects of any given pacemaker mode cannot be assessed. Blinding in crossover studies may be difficult, and investigator bias may occur. Our use of a long-term, parallel study design with quality-of-life interviewers who were unaware of patients' treatment assignments obviated many of these problems and may account for our unexpected results.

The apparently divergent results of a generic instrument (SF-36) and a cardiovascular disease-specific instrument (the Specific Activity Scale) assessing quality of life in the overall group emphasize the complexities inherent in measuring this variable in the elderly. Although it is clear from our results that dual-chamber pacing is associated with long-term improvements in cardiovascular function, the importance of aging and of the development of other conditions may overwhelm the moderate improvements in cardiovascular functional class and minimize the long-term effect on general quality of life.

The pacemaker syndrome ${ }^{20,21}$ most often mimics left-sided or right-sided congestive heart failure with or without associated left ventricular systolic dysfunction, or it may present with autonomic dysfunction, ${ }^{22}$ hypotension, and associated symptoms. The syndrome is related to the loss of synchronous atrioventricular conduction. The reported incidence of the pacemaker syndrome varies widely, from 1.7 percent $^{23}$ to 83 percent. $^{2}$ Our results mandate a cautious interpretation of the crossover statistics. Crossovers occurred when symptoms of possible pacemaker syndrome reached a clinical threshold for reprogramming to dual-chamber pacing. Consequently, it is not surprising that we report an intermediate incidence of reprogramming to a dual-chamber mode. Nevertheless, over 70 percent of patients who were assigned to ventricular pacing and were alive at the end of the study were still in their assigned mode. Thus, on the basis of quality-of-life considerations alone, many patients who receive dual-chamber pacemakers might fare just as well with ventricular systems. However, more investigative effort should be focused on finding simple ways in which to identify preoperatively the minority of patients who will prove intolerant to ventricular pacing.

The literature on cardiac pacing is replete with retrospective analyses associating dual-chamber or atrial pacing with improved clinical outcomes.,24-26 However, all these retrospective studies are flawed because pacemaker selection was not random and because clinicians selected the more expensive forms of technology for younger, less sick patients. In a late follow-up of a prospective study of patients with sinus-node dysfunction, Andersen et al. ${ }^{23}$ reported that atrial pacing reduced embolic events, atrial fibrillation, and mortality. We found that there was no significant mode-related difference in either the incidence of atrial fibrillation or any of the other prespecified clinical end points in the overall group. However, analyses of subgroups of patients with sinus-node dysfunction revealed trends similar to the findings reported by Andersen et al. ${ }^{23}$ Patients with atrioventricular block did not demonstrate any clear benefit from dual-chamber pacing. This finding in patients with atrioventricular block is consistent with 
the reported failure to find a clear difference in exercise duration in patients with atrioventricular block with rate-adaptive pacing, ventricular pacing, or dualchamber pacing. $27-30$

The design of the study did not permit maintenance of an accurate registry to compare the screened and enrolled populations. However, the demographic and clinical characteristics of the participants were very similar to those of recipients of dual-chamber pacemakers in the Medicare data base. ${ }^{26}$ Frequent ventricular pacing might be associated with the development of the pacemaker syndrome. ${ }^{31}$ However, the pacemakers used in this trial did not have accurate internal event counters, and the frequency of paced ventricular events is unknown. The use of rate adaptation may obscure differences between dual-chamber and ventricular pacing. The importance of this possibility cannot be assessed, since our study did not include a comparison group with simple ventriculardemand pacing. The difference in clinical events between groups may have been reduced by the crossover rate. The study was designed with good statistical power to detect clinically relevant differences in health-related quality of life. However, the statistical design still permitted a 20 percent likelihood of a false negative result. Finally, there was only limited statistical power to address differences in clinical events.

In the study, health-related quality of life improved dramatically after pacemaker implantation; however, general quality-of-life benefits associated with dualchamber pacing as opposed to ventricular pacing were detectable only in the subgroup of patients with sinus-node dysfunction. These benefits were moderate. The interpretation of the quality-of-life results must be tempered by the rather high crossover rates from ventricular pacing to dual-chamber pacing and by strong trends toward clinical benefit in patients assigned to dual-chamber pacing, particularly in those with sinus-node dysfunction.

Funded by a grant from Intermedics, Freeport, Tex.

We are indebted to John Garcia and Richard Sanders for their support; to the study coordinators, Kimberly Vitale, R.N., and Carolina Dedosantos, for their dedicated assistance; to Elaine Abrams, quality-of-life interviewer, for her attention to detail; and to Lori Martens for secretarial assistance.

\section{APPENDIX}

Other principal investigators of the Pacemaker Selection in the Elderly trial are as follows: J. Zimmerman, Hackensack Medical Center, Hackensack, N.J.; J. Kirchhoffer, Baystate Medical Center, Springfield, Mass.; J. Brinker, Johns Hopkins Hospital, Baltimore; J. Hayes, Marshfield Clinic, Marshfield, Wis.; N. Tullo, St. Joseph's Hospital and Medical Center, Patterson, N.J.; S. Greenberg, St. Francis Hospital, Roslyn, N.Y.; H. Weiner, Delaware Cardiology Research Foundation, Newark, Del.; C. Love, Ohio State University, Cleveland; C. Dennis, Deborah Heart and Lung Center, Browns Mills, N.J.; R. Henthorn, Christ Hospital, Cincinnati; J. Herre, Cardiology Consultants, Norfolk, Va.; O. Randall, Howard University Hospital, Washington, D.C.; D. Bush, Francis Scott Key Medical Center, Baltimore; C. Clyne, University of Pennsylvania Medical Center, Phil- adelphia; L. Beauregard, Cooper Hospital, Camden, N.J.; T. Friehling, Fairfax Hospital, Fairfax, Va.; C. Schuger, Beth Israel Deaconess Medical Center, Boston; and J. Langberg, Emory University, Atlanta.

\section{REFERENCES}

1. Samet P, Castillo C, Bernstein WH. Hemodynamic consequences of atrial and ventricular pacing in subjects with normal hearts. Am J Cardiol 1966;18:522-5.

2. Heldman D, Mulvihill D, Nguyen $H$, et al. True incidence of pacemaker syndrome. Pacing Clin Electrophysiol 1990;13:1742-50.

3. Sulke N, Dritsas A, Bostock J, Wells A, Morris R, Sowton E. "Subclin ical" pacemaker syndrome: a randomised study of symptom free patients with ventricular demand (VVI) pacemakers upgraded to dual chamber devices. Br Heart J 1992;67:57-64.

4. Dreifus LS, Fisch C, Griffin JC, Gillette PC, Mason JW, Parsonnet V. Guidelines for implantation of cardiac pacemakers and antiarrhythmia devices: a report of the American College of Cardiology/American Heart Association Task Force on Assessment of Diagnostic and Therapeutic Cardiovascular Procedures (Committee on Pacemaker Implantation). Circulation 1991;84:455-67.

5. Bernstein AD, Camm AJ, Fletcher RD, et al. The NASPE/BPEG generic pacemaker code for antibradyarrhythmia and adaptive-rate pacing and antitachyarrhythmia devices. Pacing Clin Electrophysiol 1987;10:794-9. 6. Ware JE Jr, Sherbourne CD. The MOS 36-item Short-Form Health Survey (SF-36). I. Conceptual framework and item selection. Med Care 1992;30:473-83.

7. Ware JE, Snow KK, Kosinski M, Gandek B. SF-36 health survey: manual and interpretation guide. Boston: Health Institute, New England Medical Center, 1993.

8. Goldman L, Hashimoto B, Cook EF, Loscalzo A. Comparative reproducibility and validity of systems for assessing cardiovascular functional class: ad vantages of a new Specific Activity Scale. Circulation 1981;64:1227-34.

9. Rosenqvist M, Brandt J, Schuller H. Long-term pacing in sinus node disease: effects of stimulation mode on cardiovascular morbidity and mortality. Am Heart J 1988;116:16-22.

10. Diggle PJ, Liang K-Y, Zeger SL. Analysis of longitudinal data. Oxford, England: Oxford University Press, 1994.

11. Kaplan EL, Meier P. Nonparametric estimation from incomplete observations. J Am Stat Assoc 1958;53:457-81.

12. Cox DR. Regression models and life-tables. J R Stat Soc [B] 1972;34: 187-220.

13. Bernstein $\mathrm{AD}$, Parsonnet V. Survey of cardiac pacing in the United States in 1989. Am J Cardiol 1992;69:331-8.

14. Lamas GA, Prosser AP, Edery TP, Lee MT, Berman KE, Levine PA. Age and sex bias in pacemaker selection. Circulation 1992;86:Suppl I: I-449. abstract.

15. Bonow RO, Vitale DF, Bacharach SL, Maron BJ, Green MV. Effects of aging on asynchronous left ventricular regional function and global ventricular filling in normal human subjects. J Am Coll Cardiol 1988;1 1:50-8. 16. Miller TR, Grossman SJ, Schectman KB, Biello DR, Ludbrook PA,

Ehsani AA. Left ventricular diastolic filling and its association with age. Am J Cardiol 1986;58:531-5.

17. Brinker JA. Endocardial pacing leads: the good, the bad, and the ugly. Pacing Clin Electrophysiol 1995;18:953-4.

18. Lamas GA, Dawley D, Splaine K, Folland ED, Friedman PL, Antman EM. Documented symptomatic bradycardia and symptom relief in patients receiving permanent pacemakers: an evaluation of the joint ACC/AHA pacing guidelines. Pacing Clin Electrophysiol 1988;11:1098-104.

19. Linde-Edelstam $C$, Nordlander R, Unden AL, Orth-Gomer K, Ryden L. Quality-of-life in patients treated with atrioventricular synchronous pacing compared to rate modulated ventricular pacing: a long-term, doubleblind, crossover study. Pacing Clin Electrophysiol 1992;15:1467-76. 20. Furman S. Pacemaker syndrome. Pacing Clin Electrophysiol 1994;17: $1-5$.

21. Ellenbogen KA, Gilligan DA, Wood MA, Morillo C, Barold SS. The pacemaker syndrome - a matter of definition. Am J Cardiol 1997;79: 1226-9.

22. Ellenbogen KA, Thames MD, Mohanty PK. New insights into pacemaker syndrome gained from hemodynamic, humoral and vascular responses during ventriculo-atrial pacing. Am J Cardiol 1990;65:53-9. 23. Andersen HR, Nielsen JC, Thomsen PEB, et al. Long-term follow-up of patients from a randomised trial of atrial versus ventricular pacing for sick-sinus syndrome. Lancet 1997;350:1210-6.

24. Hesselson AB, Parsonnet V, Bernstein AD, Bonavita GJ. Deleterious effects of long-term single-chamber ventricular pacing in patients with sick sinus syndrome: the hidden benefits of dual chamber pacing. J Am Coll Cardiol 1992;19:1542-9.

25. Lamas GA, Estes NM III, Schneller S, Flaker GC. Does dual chamber 
or atrial pacing prevent atrial fibrillation? The need for a randomized controlled trial. Pacing Clin Electrophysiol 1993;15:1109-13.

26. Lamas GA, Pashos CL, Normand SLT, McNeil B. Permanent pacemaker selection and subsequent survival in elderly Medicare pacemaker recipients. Circulation 1995;91:1063-9.

27. Pehrsson SK. Influence of heart rate and atrioventricular synchronization on maximal work tolerance in patients treated with artificial pacemakers. Acta Med Scand 1983;214:311-5.

28. Jutzy RV, Florio J, Isaeff DM, et al. Comparative evaluation of rate modulated dual chamber and VVIR pacing. Pacing Clin Electrophysiol 1990;13:1838-46.
29. Linde-Edelstam C, Hjemdahl P, Pehrsson SK, Astrom H, Nordlander R. Is DDD pacing superior to VVI,R? A study on cardiac sympathetic nerve activity and myocardial oxygen consumption at rest and during exercise. Pacing Clin Electrophysiol 1992;15:425-34.

30. Deharo JC, Badier M, Thirion X, et al. A randomized, single-blind crossover comparison of the effects of chronic DDD and dual sensor VVIR pacing mode on quality-of-life and cardiopulmonary performance in complete heart block. Pacing Clin Electrophysiol 1996;19:1320-6.

31. Rediker DE, Eagle KA, Homma S, Gillam LD, Harthorne JW. Clinical and hemodynamic comparison of VVI versus DDD pacing in patients with DDD pacemakers. Am J Cardiol 1988;61:323-9. 